\title{
Resolution of Dopamine in the Presence of Ascorbic Acid and Uric Acid by the Poly Oxalic Acid Modified Carbon Paste Electrode
}

\author{
P.JEEVAN JYOTI, K.GANGADHARA REDDY, V. PRABHAKER RAO, \\ M. LAVANYA and G.MADHAVI*
}

Department of Chemistry, S.V.U. College of Sciences, Sri Venkateswara University, Tirupati-517502, Andhra Pradesh, India

gmchem01@gmail.com

Received 24 December 2014 / Accepted 21 January 2015

\begin{abstract}
A novel poly oxalic acid carbon paste electrode was fabricated by electro polymerization process and characterized in this study. This poly oxalic acid modified carbon paste electrode by cyclic voltammetry (CV) and differential pulse voltammetry (DPV) exhibited an excellent electro catalytic activity towards the resolution of ascorbic acid (AA), dopamine (DA) and uric acid (UA) compared with bare carbon paste electrode. The effect of $\mathrm{pH}$ range from 5.5 to 8.0 was studied and the redox peak was $\mathrm{pH}$ dependent with a slope of $60 \mathrm{mV} / \mathrm{pH}$ and from the regression coefficient of the effect of scan rate shows that the process is adsorption controlled. The DPV study of 6.2 to $131 \mu \mathrm{M}$ concentration range of DA shows $6 \mu \mathrm{M}$ detection limit. The oxidation potentials of AA, DA and UA at the poly oxalic acid modified carbon paste electrode was shifted slightly negatively and the peak currents were much larger than the bare carbon paste electrode. DPV was used for the simultaneous determination of AA, DA and UA in their mixture, and the peak potential separations between AA and DA, DA and UA, AA and UA were $197 \mathrm{mV}, 169 \mathrm{mV}$ and $367 \mathrm{mV}$ respectively. The limit of detection for AA, DA and UA were $0.93 \mathrm{mM}, 7.4 \mu \mathrm{M}$ and13 $\mu \mathrm{M}$ respectively. This Oxalic acid modified carbon paste electrode showed many merits in stability, sensitivity, facility, economy and also applicable for real sample analysis.
\end{abstract}

Keywords: Oxalic acid, Ascorbic acid, Uric acid, Dopamine, Cyclic Voltammetry, Differential pulse voltammetry

\section{Introduction}

Neurotransmitters have received a considerable attention due to the key roles played by them in the central nervous systems of our body ${ }^{1}$. Dopamine (DA) is an important neurotransmitter in the mammalian central nervous system. Low level of DA may result in neurological disorder such as Parkinson's disease and schizophrenia ${ }^{2}$. Ascorbic acid (AA) is very popular for its antioxidant properties. Moreover, a number of studies have investigated the function of AA in gene expression and as a cosubstrate of many important dioxygenases $^{3}$. Uric acid (UA) is the primary end product of urine metabolism. It has been 
shown that extreme abnormalities of UA levels are the symptoms of several diseases, such as gout and hyperuricemia ${ }^{4}$. DA, UA and AA usually coexist in biological samples. Since the basal DA concentration is very low $(0.01-1 \mu \mathrm{M})$ while the concentration of AA and UA is generally much higher than that of DA $(100-1000 \text { times })^{2-5}$, it is essential to develop sensitive and selective methods for their determination in routine analysis. However, a major problem encountered is that UA, DA and AA are oxidized at nearly the same potential with poor sensitivity at conventional electrodes with a pronounced fouling effect resulting in poor reproducibility.The overlap of their voltammetric responses makes their simultaneous determination highly difficult ${ }^{6}$. In order to overcome this goal, numerous materials such as organic redox mediators ${ }^{7}$, nanoparticles ${ }^{8}$ and self-assembled monolayer ${ }^{9}$ have been applied as modification layer to construct the highly selective and sensitive DA biosensor.

The traditional analytical methods have been employed for the detection of DA, such as Chromatography ${ }^{10}$, Spectrophotometry ${ }^{11-12}$, Chemiluminescence ${ }^{13}$, Fluorimetry $^{14}$, Capillary Electrophoresis (CE-luminescence) ${ }^{15}$ and electrochemical methods ${ }^{16-18}$. Similarly in the electroanalytical chemistry some of the modified electrodes like nanoparticles modified electrodes $^{19-20}$, carbon ceramic electrode ${ }^{21}$, pyrolytic graphite electrode ${ }^{22}$, boron-doped diamond electrode (BDD) $)^{23}$, carbon ionic liquid electrode ${ }^{24}$, screen-printed carbon electrode $^{25}$, electrochemically oxidized $\mathrm{GCE}^{26}$ and carbon nanotube microelectrode ${ }^{27}$ are applicable for the simultaneous estimation of neurotransmitters.

Recently, polymer film and metal nanoparticles have been arose great attentions due to their wide applications in the fieldsof chemically modified electrodes ${ }^{28-29}$. Among various types of conductivepolymers ${ }^{30-31}$, polyimidazole (PIm) has many attractive features, for example the film is very stable and hard to be taken off from the surface unless the electrode is heavily polished. It has high selectivity and sensitivity due to the chemically stable homogeneous film with controlled thickness.

Herein, we have reported the formation of poly oxalic acid polymer composite via electrochemical method based on the number of cycles of redox reaction of oxalic acid, which is more facile and less time consuming than other existing methods. We have studied the electrochemical determination of DA at poly oxalic acid polymer modified electrode. To the best of our knowledge, poly oxalic acid polymercomposite has never been used for the electrochemical determination of DA. The high surface area and good conductivity of the poly oxalic acid polymer composite allows the efficient oxidation of DA. Moreover, composite electrode showed greater electrocatalytic oxidation for DA than other modified electrodes. Additionally, the practicality of this sensor towards the detection of DA in the commercial DA injection solutions has also been demonstrated.

\section{Experimental}

The electrochemical experiments were carried out with a CH-Instruments Model No. CHI610D Electrochemical work station with a connection to a personal computer was used for the electrochemical measurement and treating of data. All the experiments were carried out in a conventional three-electrode system. The electrode system contained a working carbon paste electrode with a homemade cavity of $3 \mathrm{~mm}$ diameter, a platinum wire as counter electrode and saturated calomel electrode as reference electrode. Bare carbon paste electrode was prepared by grinding $70 \%$ of graphite powder and $30 \%$ of silicon oil in an agate mortar by hand mixing for about $30 \mathrm{~min}$ to get the homogenous paste. The paste was packed into the cavity of CPE and smoothened on a weighing paper ${ }^{32}$. 


\section{Chemicals and solutions}

Analytical grade Dopamine hydrochloride, Ascorbic acid, Uric acid, sodium dihydrogen phosphate, disodium hydrogen phosphate and silicon oil were procured from Himedia Chemicals. Fine graphite powder (particle size $<20 \mu \mathrm{m}$ ) was supplied by Sigma-Aldrich chemicals.All chemicals were of analytical grade and were used without further purification. Dopamine stock solution was prepared by dissolving known quantity of it in $0.1 \mathrm{M}$ perchloricacidacid and Ascorbic Acid in double distilled water, the stock solution of Uric acid $(25 \mathrm{mM})$ was prepared in $0.1 \mathrm{M}$ sodium hydroxide solution. Phosphate buffer ( $\mathrm{pH}$ 7.0) was prepared as per the literature with $0.1 \mathrm{M} \mathrm{NaH} \mathrm{PO}_{4}, \mathrm{Na}_{2} \mathrm{HPO}_{4}$ and dissolved in double distilled water. Oxalic acid $(25 \mathrm{mM})$ was prepared in double distilled water. The $\mathrm{pH}$ values were measured with Elico Li $120 \mathrm{pH}$ meter. All measurements were carried out at the room temperature.

Preparation of bare carbon paste electrode and Oxalic acid polymer modified carbon Paste electrode

The bare carbon paste electrode was prepared by adding the graphite powder and silicon oil at the ratio of $(70: 30 \%)$ in an agate mortar to obtain a homogenous carbon paste. The polymer film modified CPE was prepared by the electrochemical polymerization of Oxalic acid on a carbon paste electrode in $0.1 \mathrm{M}$ phosphate buffer solution of $\mathrm{pH} 7.0$ containing 1.0 $\mathrm{mM}$ of Oxalic acid with cyclic voltammetric sweeps in the potential range of $-0.8 \mathrm{~V}$ to $1.2 \mathrm{~V}$ at the scan rate of $50 \mathrm{mV} / \mathrm{s}$. The surface of the electrode was washed with distilled water.

\section{Results and Discussion}

\section{Electrochemical polymerization of oxalic acid on the carbon paste electrode}

Oxalic acid polymer film modified CPE was fabricated with oxalic acid on the surface of CPE by cyclic voltammetric method in PBS ( $\mathrm{pH} 7.0$ ) containing $1 \mathrm{mM}$ of Oxalic acid. Electropolymerization was carried out between the potential $-0.75 \mathrm{~V}$ to $1.25 \mathrm{~V}$ at a scan rateof $50 \mathrm{mV} / \mathrm{s}$ in 20 cycles as shown in Figure 1. During the polymerization process, an anodic peak potential at $0.714 \mathrm{~V}$ was observed due to the formation of polymer layer of oxalic acid on the surface of the electrode. The redox peak current increases withan increase in the number of cyclic voltammetric scans, indicating that an electro-conductive polymer film was formed on the electrode surface. The reaction mechanism may be characterized as follows, Oxalic acid was oxidized to form free radical which combines with the surface of $\mathrm{CPE}$, resulting in the feasible structure of electropolymerized poly OAMCPE (Scheme 1), and then the modified carbon paste electrode was rinsed with distilled water.

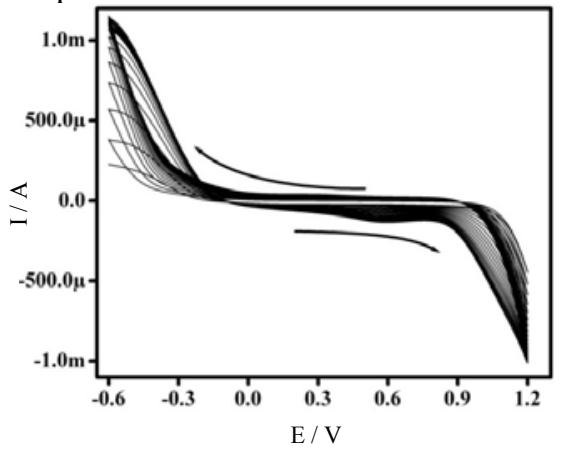

Figure 1. Cyclic voltammograms for the electrochemical polymerization of $1 \mathrm{mM}$ Oxalic acid on a carbon paste electrode at the scan rate of $50 \mathrm{mVs}^{-1}$ 


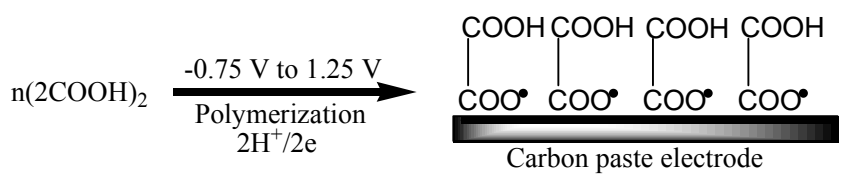

Scheme 1. Electro polymerization of oxalic acid

\section{The response of DA at the bare CPE and OAMCPE}

Figure 2 shows the cyclic voltammograms of $0.1 \mathrm{mM}$ DA at bare carbon paste electrode (dotted line) and the OAMCPE with scan rate of $50 \mathrm{mV} / \mathrm{s}$. At the BCPE, the difference between the anodic peak potential (Epa) $0.412 \mathrm{~V}$ and the cathodic peak potential (Epc) $0.200 \mathrm{~V}$ is reversible voltammogram with $\Delta \mathrm{Ep}($ Epa-Epc $)=0.212 \mathrm{~V}$. However, DA peak currents were significantly increased at the OAMCPE, with the anodic peak at $\Delta 0.328 \mathrm{~V}$ and the corresponding cathodic peak potential is $0.246 \mathrm{~V}$ and the resulting $\Delta \mathrm{Ep}=0.037 \mathrm{~V}$. Compared with BCPE a remarkable enhancement in the peak currents with the reduction of over potential indicates the catalytic effect of the poly oxalic acid polymer layer. The mechanism may be the polymer layer combining with the hydrogen bond of the hydroxyl group of DA, which activates the hydroxyl and weakens the bond energy of $\mathrm{O}-\mathrm{H}$ and improves the electron transfer rate. At the same time, high surface area of the poly oxalic acid improves the electrode contact area for DA.

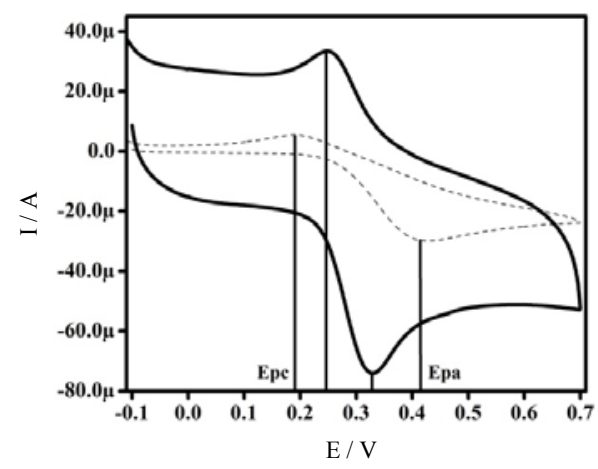

Figure 2. Cyclic voltammograms of bare carbon paste electrode (dotted line), poly oxalic acid carbon paste electrode using $0.1 \mathrm{mM}$ DA in $0.1 \mathrm{M}$ PBS $(\mathrm{pH}=7.0)$ at scan rate of $50 \mathrm{mV} \mathrm{s}^{-1}$

\section{Stability and reproducibility of the OAMCPE}

The stability and reproducibility of the OAMCPE electrode was studied in a sensitive and selective manner for the determination of DA and is shown in Figure 3. The anodic peak currents for dopamine were almost stable for 15 cycles. From these results the OAMCPE has produced stable anodic peak currents with negligible change in the redox peak currents of DA was observed.

\section{Effect of $\mathrm{pH}$ value on the determination of DA at the OAMCPE}

The $\mathrm{pH}$ of the supporting electrolyte shows significant influence on the determination of DA by electrocatalysis of OAMCPE by affecting both peak currents and peak potentials. The effect of $\mathrm{pH}$ value on the determination of DA in PBS solution at OAMCPE was carefully investigated in a wide $\mathrm{pH}$ range of 5.5-8.0. Figure 4 illustrates the dependences of the DA anodic peak current and anodic potential $[\mathrm{E}(\mathrm{V})]$ on the $\mathrm{pH}$ of buffer solution. It could be seen that the anodic peak current of DA increases with increasing $\mathrm{pH}$ value until it reaches 
7.0, (shown with (-口-) square symbol) and then there was gradual decrease in the peak current of DA until it reaches 8.0. The anodic peak potential of DA shifts towards lower potential with the increase of the $\mathrm{pH}$ value of solution and depends linearly on the $\mathrm{pH}$ value in the range of 5.5-8.0 with a slope of $0.0603 \mathrm{~V} / \mathrm{pH}$. $\left(\mathrm{r}^{2}=0.9721\right)$ (shown with closed circles $(-\bullet-))$. It demonstrates that the redox of DA undergoes a two electron and two proton processes, which was consistence with that reported in the literature ${ }^{33}$.

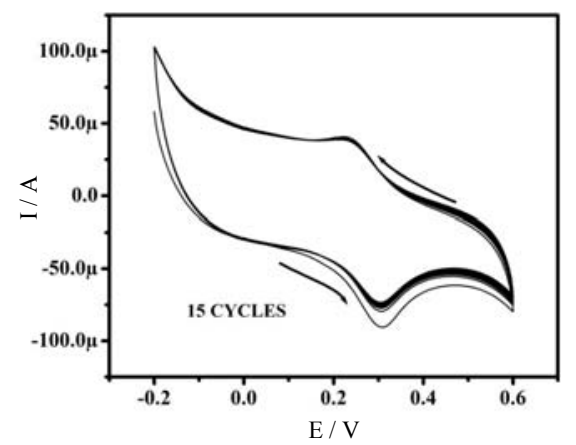

Figure 3. Stability and repeatability study of OAMCPE at $0.1 \mathrm{mM}$ DA

\section{Effect of scan rate}

The effect of scan rate for $0.1 \mathrm{mM}$ DA in $0.1 \mathrm{M}$ PBS at $\mathrm{pH} 7.0$ was studied by $\mathrm{CV}$ at OAMCPE. The modified electrode shows an increase in the redox peak currents with an increase in the scan rate $\left(50\right.$ to $\left.500 \mathrm{mVs}^{-1}\right)$. The graph of redox peak current (Ipa) vs. scan rate ( $v$ ) was plotted and a good linearity between scan rates and peak current was obtained as shown in Figure 5. The redox peak currents were proportional to $(v)^{1 / 2}$. The correlation coefficient $\left(\mathrm{r}^{2}\right)$ of Ipa and Ipc were 0.9968 and 0.99735 respectively, which indicates that the electrode reaction was an adsorption controlled process. In the above cyclic voltammograms, a pair of cathodic and anodic peaks of DA were appeared symmetrically and the potential separation of the two peaks was close to $60 / \mathrm{n} \mathrm{mV}(\mathrm{n}=2)$ at a low scan rate. It could be inferred that there was a quasi-reversible reaction on the Oxalic acid modified carbon paste ${ }^{33}$.

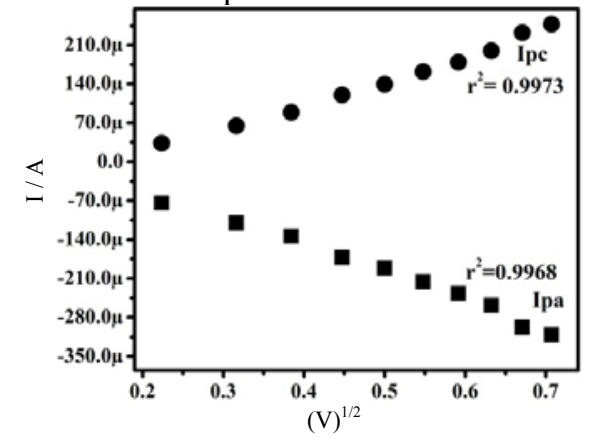

Figure 5. Graph shows the linear relationship between the peak current and the scan rate

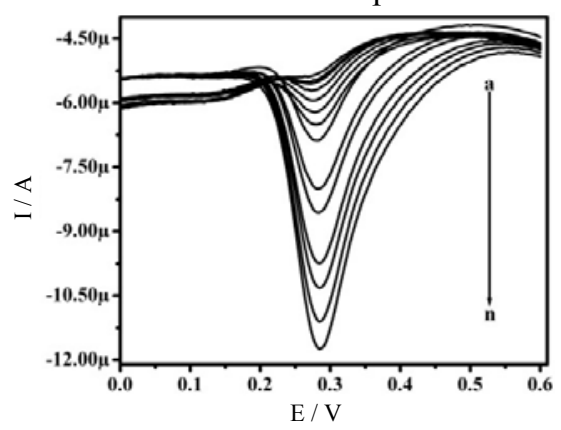

Figure 6. Series of differential pulse voltammograms (6.2 to $131 \mu \mathrm{M}$ (a to $\mathrm{n})$ ) obtained for DA at OAMCPE in $0.1 \mathrm{M}$ of pH 7.0 phosphate buffer solution 


\section{Concentration effect of $D A$}

The differential pulse voltammetric technique was used for the analysis of DA concentration which was varied from $6.2 \mu \mathrm{M}$ to $131 \mu \mathrm{M}$ and is shown in Figure 6 for the OAMCPE.

The concentration of DA was increased from 6.2 to $131 \mu \mathrm{M}$ and the corresponding graph of Ipa versus concentration of DA showed an increase in the anodic peak current with the linear regression equation as Ipa $(\mu \mathrm{A})=0.0517(\mathrm{C} / \mu \mathrm{M})+5 \mu \mathrm{M}\left(\mathrm{n}=14, \mathrm{R}^{2}=0.998\right)$ and is shown in Figure 7. The detection limit and quantification limit were calculated by using the formulae $\mathrm{e}^{34-36}$.

$$
\begin{aligned}
& \mathrm{LOD}=3 \mathrm{~S} / \mathrm{M} \\
& \mathrm{LOQ}=10 \mathrm{~S} / \mathrm{M}
\end{aligned}
$$

Where $\mathrm{S}$ is the standard deviation and $\mathrm{M}$ is the slope obtained from the calibration plots. Thedetection limit of dopamine was found to be $6 \mu \mathrm{M}$ and the quantification limit is $22 \mu \mathrm{M}$.

\section{Resolution of DA with UA and FA}

Figure 8 is the cyclic voltammograms obtained for the electrochemical response of DA $(10 \mu \mathrm{M})$, UA $(100 \mu \mathrm{M})$ and AA $(1 \mathrm{mM})$ at bare CPE (curve a), the OAMCPE (curve b) in $0.1 \mathrm{M}$ phosphate buffer solution of $\mathrm{pH}$ 7.0. At bare CPE, a well redox peak potential of DA \& AA was not observed and with OAMCPE it showed a significant redox peak potential for DA \& AA along with UA with various potential differences of DA, UA and AA 489, 344, and $97 \mathrm{mV}$ respectively.

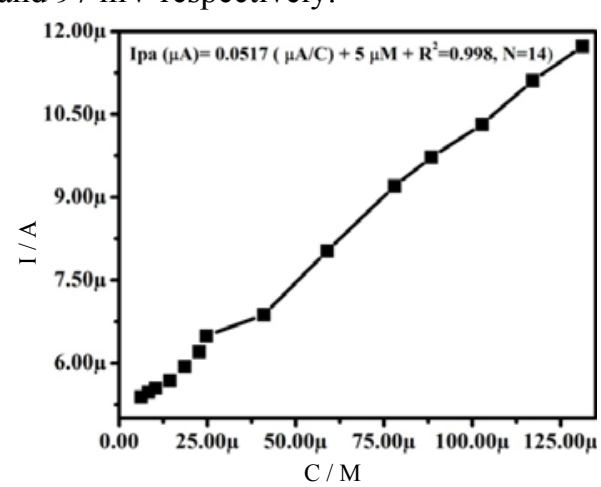

Figure 7. Graph of Ipa vs. concentration of Dopamine

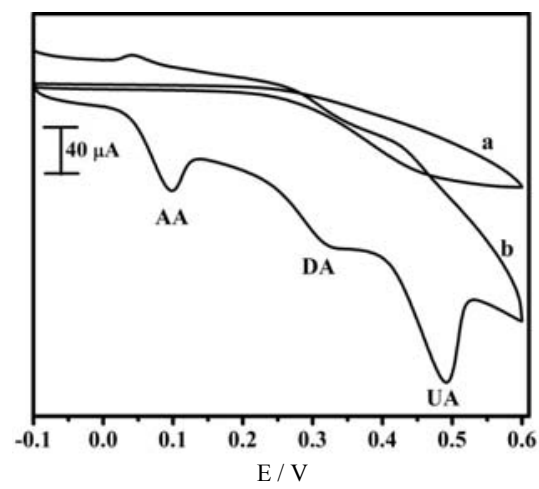

Figure 8. Cyclic voltammograms obtained for the electrochemical response of $10 \mu \mathrm{M}$ of DA $200 \mu \mathrm{M}$ of UA, $1 \mathrm{mM}$ of AA at bare CPE (curve a) and at OAMCPE (Curve b) in $0.1 \mathrm{M}$ phosphate buffer solution of (pH7.0), scan rate $50 \mathrm{mVs}^{-1}$

The main objective of this study was to detect DA, UA, and AA simultaneously. The applicability of the OAMCPE for the simultaneous determination of DA, UA, and AA was demonstrated by simultaneously changing the concentrations of DA, UA, and AA. The differential pulse voltammetric results showed that the simultaneous determination of DA, UA and AA with three well-distinguished anodic peaks with potentials at 426, 258 and $9 \mathrm{mV}$, corresponding to the oxidation of UA, DA and AA, respectively, were observed at OAMCPE (Figure 9 A). In contrast, the bare electrode showed no significant separation in the voltammetric signals of these substances. The corresponding graphs of the anodic peak current versus various concentrations of DA(10-48 $\mu \mathrm{M}), \mathrm{UA}(100-489 \mu \mathrm{M}), \mathrm{AA}(1-4.8 \mathrm{mM})$ showed a linear relationships with linear regressions for $\mathrm{B}(\mathrm{DA}) \mathrm{Y}(\mu \mathrm{A})=0.751 \mathrm{x}+1.654 \times 10^{-4}, \mathrm{C}$ 
(UA) $\mathrm{Y}(\mu \mathrm{A})=0.2755 \mathrm{x}+4.296 \times 10^{-5}$, D $(\mathrm{FA}) \mathrm{Y}(\mu \mathrm{A})=0.0136 \mathrm{x}+2.157 \times 10^{-5}$, the correlation coefficient for these linear graphs was $0.991,0.994$ and 0.991 respectively with OAMCPE which is shown in Figure 9. B, C, D respectively.
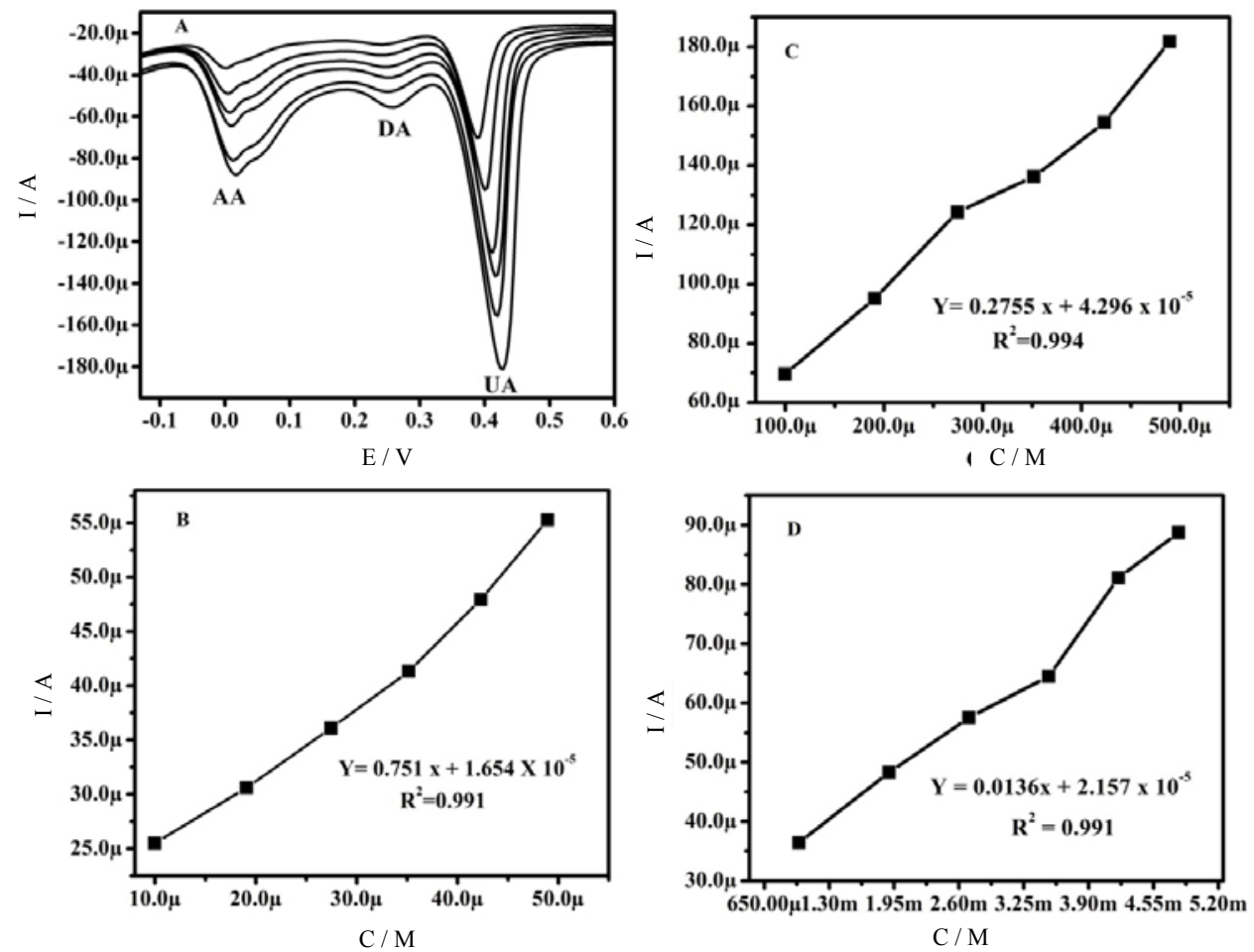

Figure 9. (A) Differential pulse voltammograms of OAMCPE in $0.1 \mathrm{M}$ phosphate buffer solution ( $\mathrm{pH}$ 7.0) containing different concentrations of DA, UA and AA (from inner to outer) mixed solutions of $9.9+99+0.95,19+190+1,27+274+2,35+351+3.5,42+423+4.2$ and $48+489+4.89$, respectively, among three set values first value is the concentration of DA in $\mu \mathrm{M}$, the second value is the concentration of UA in $\mu \mathrm{M}$ and the last value is the concentration of AA in mM. Remain plots of the peak currents as a function of DA (B), $\mathrm{UA}(\mathrm{C})$ and AA (D) versus concentration, respectively.

Effect of various concentration changes of DA in the presence AA, UA / UA in the presence $A A, D A / A A$ in the presence DA,UA.

Figure $10 \mathrm{~A}, \mathrm{~B}, \mathrm{C}$ shows the differential pulse voltammograms of OAMCPE for a fixed concentration of UA $(100 \mu \mathrm{M}), \mathrm{DA}(10 \mu \mathrm{M})$ and AA with concentrations varying from 1 to $4.80 \mathrm{mM}$. Similarly UA $(100 \mu \mathrm{M})$, AA $(1 \mathrm{mM})$ and DA with concentrations varying from 10 to $48 \mu \mathrm{M}$ and DA $(10 \mu \mathrm{M})$, AA $(1 \mathrm{mM})$ and UA concentrations varying respectively in $0.1 \mathrm{M}$ phosphate buffer $(\mathrm{pH}$ 7.0). Obviously anodic peak currents increase with increasing concentrations of AA, DA and UAwhile the anodic peak currents of UA, DA and UA, AA and DA, AA remain constant. A good linearity between Ipa and the concentrations variation of AA, DA, UA were obtained respectively and is shown in the Figure. $10 \mathrm{D}, \mathrm{E}$ and F respectively.Furthermore, it was observed that in the presence of high concentrations of remain analytes the detection of lower concentration of AA, DA and UA is still possible. 
The OAMCPE showed a good selectivity for the electrochemical detection of DA, AA and UA in the presence of remaining analytes. The corresponding graphs of anodic peak current versus concentration of $\mathrm{AA}, \mathrm{DA}$, UA showed a linear regression $\mathrm{Y}(\mu \mathrm{A})=0.007 \mathrm{x}+$ $3.791 \mathrm{c} \times 10^{-5} \mathrm{R}^{2}=0.9879, \quad \mathrm{Y}(\mu \mathrm{A})=0.659 \mathrm{x}+1.598 \times 10^{-5} \quad \mathrm{R}^{2}=0.9944$ and $\mathrm{Y}(\mu \mathrm{A})=1.6325 \mathrm{x}+$ $3.189 \times 10^{-6} \mathrm{R}^{2}=0.9870$ respectively and the detection limits of AA $0.93 \mathrm{mM}$, DA7.4 $\mu \mathrm{M}$ and $\mathrm{UA} 13 \mu \mathrm{M}$ were found.
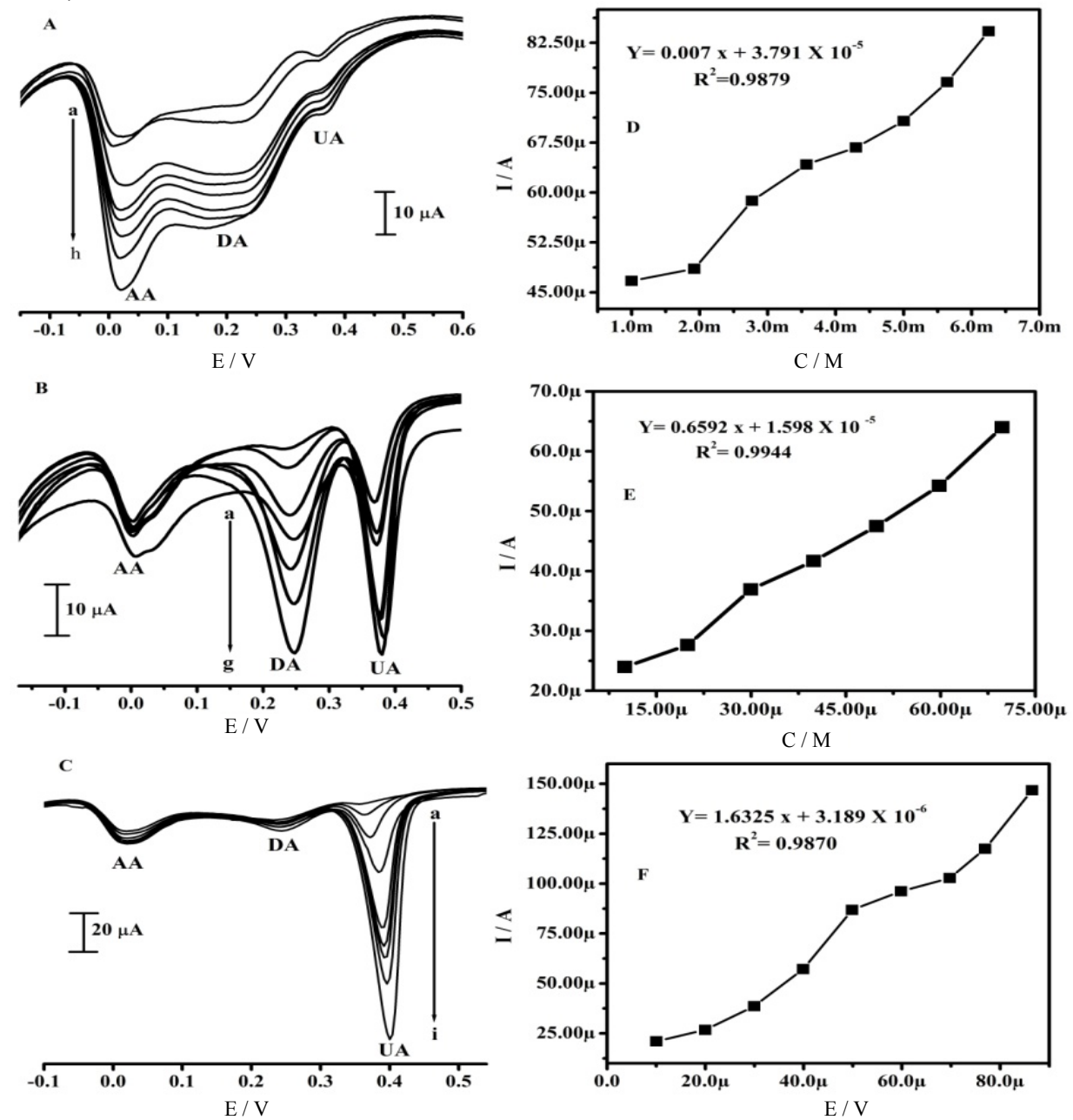

Figure 10. A) Differential pulse voltammograms at the OAMCPE for UA, DA and with different concentrations of AA, B)UA, AA and with different concentrations of DA, C) DA, $\mathrm{AA}$ and with different concentrations of $\mathrm{UA}$, in $0.1 \mathrm{M}$ phosphate buffer solution of $\mathrm{pH}$ 7.0. The plots, D) shows Ipa versus AA concentration, E) shows Ipa versus DA concentration, F) Shows Ipa versus UA concentration variations.

\section{Application to real system}

Practical application of modified electrode was demonstrated by quantitative determination of DA in human blood serum samples (obtained from the Health Centre, Sri Venkateswara 
University, Tirupati, Andhra Pradesh, India). The procedure was as followed: $2 \mathrm{~mL}$ of human serum sample without any pretreatment was diluted to $100 \mathrm{~mL}$ with $\mathrm{pH} 7.0$ phosphate buffer. Different volumes of this solution were mixed with a known volume concentration of DA solution and also of known concentration, to obtain different concentrations of spiked DA. Similarly, a drug injection capsule containing $200 \mathrm{mg}$ of dopamine hydrochloride in $5 \mathrm{~mL}$ sterilized water (Neon laboratories Private Ltd, India) was suitably diluted to provide different known standard concentrations of DA which were analyzed by DPV using the OAMCPE. Each experiment was carried out at least 5 times and the results were presented in Table 1 . The obtained recovery and relative standard deviation (RSD) were good, indicating the efficiency of the OAMCPE.

Table 1. Determination of DA in drug injection and human blood serum sample $(n=5)$

\begin{tabular}{ccccc}
\hline Samples & Spiked DA sample, $\mathrm{mM}$ & Found, $\mathrm{mM}$ & Recovery, \% & RSD, \% \\
\hline \multirow{3}{*}{ Blood serum } & 0.1 & 0.095 & 95 & 3.5 \\
& 0.2 & 0.194 & 97 & 3.2 \\
Drug & 0.3 & 0.297 & 99 & 1.4 \\
injection & 0.1 & 0.097 & 97 & 3.0 \\
& 0.2 & 0.203 & 101 & 2.5 \\
& 0.3 & 0.294 & 98 & 1.1 \\
\hline
\end{tabular}

\section{Conclusion}

A simple and sensitive electrochemical sensor was fabricated based on electrochemically polymerized carbon paste electrode surface with Oxalic acidfor the determination of DA in the presence of AA, UA. The results demonstrated that the electrooxidation of DA at the surface of the oxalic acid modified electrode was occurred at a potential of about $0.0843 \mathrm{~V}$ which is less positive than that of the bare carbon paste electrode. The peak separations with detected potential differences of 168, 256 and $424 \mathrm{mV}$ between DA-UA, DA-AA and UAAA respectively were large enough to determine DA, UA and AA individually and simultaneously. Finally, the applicability of this electrode was tested for the determination of DA in pharmaceutical and also in clinical samples.

\section{References}

1. Wightman R M, May L J and Michael A C, Anal Chem., 1988, 60(13), 769A-779A; DOI:10.1021/ac00164a001

2. Wightman R M, May L J and Michael A C, Anal Chem., 1988, 60(13), 769A-793A; DOI:10.1021/ac00164a718

3. Arrigoni O and Tullio M C D, Biochim Biophys Acta. 2002, 1569(1-3), 1-9.

4. Dutt V V S E and Mottola H A, Anal Chem., 1974, 46(12), 1777-1781; DOI:10.1021/ac60348a041

5. Zen J M and Chen P J, Anal Chem., 1997, 69(24), 5087-5093; DOI:10.1021/ac9703562

6. Nada F A, Ahmed G and Rasha A A, Bioelectrochem., 2010, 80(2), 132-141; DOI:10.1016/j.bioelechem.2010.07.002

7. Chen J H, Zhang J, Lin X H, Wan H Y and Zhang S B, Electroanalysis, 2007, 19(5), 612-615; DOI:10.1002/elan.200603755

8. Li F H, Chai J, Yang H F, Han D X and Niu L, Talanta, 2010, 81(3), 1063-1068; DOI:10.1016/j.talanta.2010.01.061

9. Zhang Y Z, Pan Y, Su S, Zhang L P, Li S P and Shao M W, Electroanalysis, 2007, 19(16), 1695-1701; DOI:10.1002/elan.200703901 
10. Carrera V, Sabater E, Vilanova E and Sogorb M A, J Chromatogr B, 2007, 847(2), 88-94; DOI:10.1016/j.jchromb.2006.09.032

11. Nagaraja P, Srinivasa Murthy K C, Rangappa K S and Gowda N M M, Talanta, 1998, 46(1), 39-44; DOI:10.1016/S0039-9140(97)00245-2

12. Maminski M, Olejniczak M, Chudy M, Dybko A and Brzozka Z, Anal Chim Acta, 2005, 540(1), 153-157; DOI:10.1016/j.aca.2004.09.011

13. Li J and Lu J, Chinese J Anal Chem., 1997, 25, 314-316.

14. Nohta H, Yukizawa T, Ohkura Y, Yoshimura M, Ishida J and Yamaguchi M, Anal Chim Acta, 1997, 344(3), 233-240; DOI:10.1016/S0003-2670(96)00614-9

15. Zhu R and Kok W T, Anal Chem., 1997, 69(19), 4010-4016;

DOI:10.1021/ac970323m

16. Ali S R, Ma Y F, Parajuli R R, Balogun Y, Lai W Y C and He H X, Anal Chem., 2007, 79(6), 2583-2587; DOI:10.1021/ac062068o

17. Liu Y, Huang J S, Hou H Q and You T Y, Electrochem Commun., 2008, 10(10), 1431-1434; DOI:10.1016/j.elecom.2008.07.020

18. Jia N Q, Wang Z Y, Yang G F, Shen H B and Zhu L Z, Electrochem Commun., 2007, 9(2), 233-238; DOI:10.1016/j.elecom.2006.08.050

19. Huang J S, Liu Y, Hou H Q and You T Y, Biosens Bioelectron., 2008, 24(4), 632 637; DOI:10.1016/j.bios.2008.06.011

20. Atta N F, Kady M F E and Galal A, Sens Actuators B: Chem.,, 2009, 141(2), 566574; DOI:10.1016/j.snb.2009.07.002

21. Salimi A, Mam K H and Hallaj R, Talanta, 2006, 70(4), 823-832;

DOI:10.1016/j.talanta.2006.02.015

22. Silva R P, Lima A W O and Serrano S H P, Anal Chim Acta, 2008, 612(1), 89-98; DOI:10.1016/j.aca.2008.02.017

23. Siew P S, Loh K P, Poh W C and Zhang H, Diamond Relat Mater., 2005, 14(3-7), 426-431; DOI:10.1016/j.diamond.2004.11.016

24. Safavi A, Maleki N, Moradlou O and Tajabadi F, Anal Biochem. 2006, 359(2), 224229; DOI:10.1016/j.ab.2006.09.008

25. Prasad K S, Muthuraman G and Zen J M, Electrochem Commun., 2008, 10(4), 559563; DOI:10.1016/j.elecom.2008.01.033

26. Thiagarajan S, Tsai T H and Chen S M, Biosens Bioelectron., 2009, 24(8), 27122716; DOI:10.1016/j.bios.2008.12.010

27. Hocevar S B, Wang J, Deo R P, Musameh M, Ogorevc B Electroanalysis. 2005, 17(5-6), 417-422; DOI:10.1002/elan.200403175

28. Liu A L, Zhang S B, Chen W, Lin X H and Xia X H, Biosens Bioelectron., 2008, 23(10), 1488-1495; DOI:10.1016/j.bios.2008.01.001

29. Wang P, Li Y X, Huang X, Wang L Talanta. 2007, 73(3), 431-437;

DOI:10.1016/j.talanta.2007.04.022

30. Lin K C, Tsai T H and Chen S M, Biosens Bioelectron., 2010, 26(2), 608-614; DOI:10.1016/j.bios.2010.07.019

31. Kalimuthu P, John S A Talanta. 2010, 80(5), 1686-1691; DOI:10.1016/j.talanta.2009.10.007

32. Gangadhara Reddy K, Madhavi G, Kumara Swamy B E, Sathish Reddy, VijayaBhaskar Reddy A and Madhavi V, J Mol Liq., 2013, 180, 26-30; DOI:10.1016/j.molliq.2012.12.032

33. Reddy S, Swamy B E K,Chandra U, Mahathesha K R, Sathisha T V and Jayadevappa H, Anal Methods, 2011, 3, 2792-2796; DOI:10.1039/C1AY05483J 
34. Hegde R N, Kumara Swamy B E, Shetty N P and Nandibewoor S T, J Electroanal Chem., 2009, 635, 51.

35. Madhavi G, Damodar J, Mohan S K and Reddy S J, Bull Electrochem., 1998, 10, 209-213.

36. Madhavi G, Damodar J, Mohan S K, Reddy S J, Bull Electrochem., 1999, 15, 535. 